\title{
The Promise and Practice of E-Learning within Complex Tertiary Environments
}

\author{
E. Marcia Johnson and Ruth Walker \\ The University of Waikato, Hamilton, New Zealand \\ marcia@waikato.ac.nz \\ rmwalker@waikato.ac.nz
}

\begin{abstract}
In advance of a change in learning management systems at a tertiary institution in New Zealand, the authors undertook a research study, the purpose of which was to provide a 'snap-shot' of existing online instructional practice within their School. They sought to identify existing pedagogical and technical issues and staff attitudes and preparedness for the new software. Although they found considerable staff good will toward e-learning, a number of problems were identified in the study. Findings from research have been organized and are discussed within five categories, including vision, skills, incentives, resources, and action plan. Conclusions describe plans for reorganizing how and in what manner e-learning can be supported within complex social environments, such as universities, when resources are limited.
\end{abstract}

\section{Background to the study}

At the University of Waikato in New Zealand a new learning management system (Moodle) has recently been selected to replace the proprietary software system (WebCrossing), which has supported e-learning since 2000. This research study was designed to provide a 'snapshot' of existing online instructional practice within the authors' School so as to identify existing issues (both pedagogical and technological) and staff attitudes and preparedness for the change. Much has been published about the potential of technology to transform education, but realizing that potential has frequently proved difficult [1], [2].

\section{The research project}

The four main goals of the project were to investigate, describe, and evaluate the major features of Webcrossing, as used by the School's teaching staff; the activities and tasks that could be best supported by an LMS or other software tools; the ideas and plans that staff had about elearning in the future; and to prepare an overall description of the state of e-learning within the School.

In order to identify potential research participants, a list of all courses taught in the School was obtained, including the modes in which they were offered (fully online or online-supported, for example). From over 800 courses, only those that indicated some online component were selected and the courses' instructors identified. This provided a final list of 60 people from whom approximately half were contacted and invited to participate in the study. In addition, selected members of the School's administration and the University EEducation committee were interviewed in order to provide a more complete overview of computing practice, attitudes, and plans.

In total 15 interviews (with 17 people) were conducted using a semi-structured interview form consisting of twenty questions. Each interview lasted for between 6090 minutes. Although we did not obtain a representative sample of staff across all departments, we believed that we did obtain a clear view of e-learning practice within the School and insight into university-level planning. However, one limitation of this study is that some elearning initiatives were possibly over-looked.

\subsection{Description of the participants}

The range of subjects taught within the School is wide and participants were selected from Applied Linguistics, French, Geography, German, History, Linguistics, Media Studies, Psychology, and Sociology. In addition, the School's computer consultants, website designer, and office manager were included. Although none of the latter used the LMS for instructional purposes, they were all involved in the provision of computer support or with the design of instructional (computing) support systems. Academic staff ranged from full Professor to Senior Tutor, teaching at both undergraduate and graduate levels.

The interview form contained three sections with questions relating to fully online courses, blended learning courses, and ideas for the future. It's important to note that the questions about online or blended learning were identical except for the first question, which distinguished between how content was structured within the different delivery modes. Participants were asked to describe online tools that they used (within the LMS), tools with which they were familiar but did not use (and why), other electronic teaching tools they used, perceived advantages and disadvantages of online teaching, whether or not there was sufficient support (at the School, 
department, and technical levels) for online teaching, and what they would like to be able to do in the future.

\subsection{Description of ClassForum}

For the past seven years, the university's learning management system (LMS) has been hosted on proprietary software called WebCrossing, which has been implemented at the University under the name ClassForum. WebCrossing software focuses on the creation and management of online communicative environments as opposed to being just a means of storing and distributing course content.

Within ClassForum, there exist a range of tools to support online collaborative work, including discussions (both private and public), wikis, polls, surveys, synchronous chat, peer review, and the ability to establish private groups with random or selective assignment of students to groups. In addition, there are calendaring and student list access tools as well as folders in which documents or course information can be stored or made available for downloading. Using the software had become easier since its initial installation through the addition of specially programmed 'wizards', but we were interested in which tools were most frequently used and the pedagogical approaches teachers used.

\section{Findings and discussion}

The intensive format of the interviews yielded interesting, remarkably consistent (across all participants), but not entirely unexpected, results. From the authors' perspective, the results were less surprising than was the fact that the same problems seem to emerge over and over again within tertiary environments [3], [4]. Butler (2006) in his description of the management of successful organizational change within computer-supported instructional environments identified five key, interacting factors, including vision, skills, incentives, resources, and action plan [5]. It is within these categories that our findings have been grouped and will be discussed.

\subsection{Lack of vision}

Technically, the University of Waikato does not fall within this category as there is a publicly-stated vision for e-learning. According to the University website, elearning is an important area and one key strategic goal is "encouraging academic excellence, fostering innovative teaching methods and enhancing the learning experience and thinking skills of students" [6]. Among the actions to be followed to achieve this objective, the policy document states "1.5 Develop innovative teaching and learning methods that, for example, normalise e-learning as an integrated dimension of teaching to enhance student learning" [6].

However, while it is the case that 'e-learning' is included within the University's Strategic Plan, a definition of what is intended by the term is not. Understanding of what is meant by 'e-learning' can vary across different constituent groups (teachers, administrators, funding agencies, and students) and ranges from a preoccupation with self-directed learning material organized on a CD or website, to the use of technology to supplement campus-based, face-to-face teaching and learning (for example). Thus the lack of a clear definition within our particular instructional context must be viewed as highly problematic. Ambiguity about what e-learning means, combined with a lack of skills, incentives, resources, and a coherent action plan, severely compromise the ability of staff to achieve the University's e-learning vision.

\subsection{Lack of skills}

Before beginning our discussion about lack of skills, we wish to emphasize that we found tremendous good will among respondents and some inventive uses of computers to support teaching and learning. Teachers and technical support staff had clearly thought deeply about the use of technology, but a lack of a cohesive community of online practitioners within the School had limited its elearning achievements.

Although most respondents had attended training sessions on how to use ClassForum and felt that the workshops had adequately addressed technical issues, almost everyone felt that in recent years, they had received limited or no training on how to incorporate technology, in a pedagogically sound manner, into their teaching. A common theme occurring throughout the interviews was that e-learning was extremely timeconsuming and yet, upon closer examination, we believed that the real issue was lack of skills in effective online instructional practice. It is well known that existing courses and pedagogical approaches cannot be simply transferred from a face-to-face context into an online format [7], [8]. Many staff reported online instructional practices that we would consider to be pedagogically tedious and which could (and did) lead to increased workloads. For example, many teachers spent hours responding to multiple individual email messages from students when much more efficient and effective communication could be supported through ClassForum. Staff also reported reluctance to plan or deliver fully online papers, as they believed the increase in workload would not be manageable. These findings are certainly not unique to Waikato [3], [2], but the implication here is that knowledge from other university contexts was not systematically informing our instructional practice. 
Another indication of lack of skill in online pedagogy was reflected through the types of tools predominantly used by staff. Most teachers used the LMS merely as a repository for teaching materials while the wide range of ClassForum's collaborative tools remained unknown or under-utilized. Although the LMS does provide an efficient means to store and distribute course-related material, its potential to transform teaching from a teacher-directed delivery model to a more socially constructivist model in which students are actively involved in the creation of knowledge was not widely explored. This is in spite of the fact that there is ample research evidence illustrating the enhanced learning that can emerge from such constructivist environments [10], [11], [12], [13]. Also, students increasingly expect to find technology-supported teaching in higher education [14].

\subsection{Lack of incentives}

Although a properly functioning e-learning environment does not need to consume enormous amounts of a teacher's time [15], it remains the case that the initial transformation of a paper from face-to-face mode to online-supported or fully online does involve a substantial (initial) investment of time. Online pedagogy requires a major 'rethink' of how students will be organized, how content is to be presented, and how assessments will be undertaken (for example), and all of these aspects of online teaching must be carefully considered [15], [7], [9] during the course planning phase. In addition, the initial setup of papers within an LMS (whether it be open source or proprietary) so as to achieve clear and logical learning pathways for students, requires time, planning, and skills.

However, according to our respondents, there was little (if any) encouragement, support, or recognition at the School level of staff efforts to integrate online instructional practice into their courses. There was no reduction in teaching (work) loads so as to facilitate the transformation of papers to online formats, and perhaps more importantly, there was no formal recognition, through the promotion process (or through any other mechanism), of e-learning leadership. Most staff appeared to have invested some time adapting their papers to the ClassForum environment within the first couple of years of it being introduced, but had not persisted beyond the basic level of using it. As already stated, the predominant use was for document storage and distribution. We believe that lack of incentives, in any form, has been a major contributing factor to the uneven and limited application of e-learning within the School.

\subsection{Lack of resources}

Respondents were asked about their perceptions of resources and support for e-learning at the departmental, School, and University levels. It soon became clear that departmental resources and support for e-learning were unevenly applied across the School; some departments were very supportive of e-learning initiatives, while others provided little formal encouragement and no additional resources (although no-one reported being actively discouraged from integrating technology into their teaching).

At the School level, virtually all respondents stated that no support had been made available for e-learning. Some staff also reported a perceived lack of knowledge and understanding about e-learning at the top administrative levels.

At the University level, staff repeatedly mentioned the excellent level of support that had previously been available through an e-learning support group housed centrally in Information \& Technology Services (ITS). Not only did that group provide training sessions in which the mechanics of software were taught, one-on-one tutorial advice on pedagogical issues was available, either by appointment, in weekly 'drop-in' sessions at the ITS building, or even in one's own office. One staff member in particular was complimented over and over again for the depth of his technical and pedagogical expertise but the departure of this group (13 highly trained and experienced people) from the University into a separate commercial enterprise was generally lamented. Respondents did not believe that the expertise lost when the group left the university had been adequately replaced within ITS, our School, nor through a more recently established E-Education Committee. In fact, many respondents admitted that if they had an e-learning problem, they really didn't know whom to call other than the central 'Help' desk. All staff mentioned their preference for having a staff member housed within the School to fill a co-ordinating role, bringing together both technical and teaching staff.

\subsection{Lack of an action plan}

Although some staff had actively collaborated with colleagues within their departments to integrate ClassForum into their teaching, for the most part, they were not aware of what teachers in other departments were doing. This finding is predictable [1] given that the overwhelming perception of staff was a lack of direction, support, and resources at the School level for e-learning. Without an overall strategic plan linked into carefully staged actions, the authors are concerned that e-learning developments will continue to stagnate in the School. Further, this situation could be exacerbated as staff will be 
required to learn a completely new set of technical skills once Moodle has been implemented. As has been stated previously, 'e-learning' involves more than just using an LMS as a bulletin board.

During the interviews, some staff stated that they wanted to be able to integrate more recent applications such as podcasting into their teaching. This was particularly the case within foreign language courses in which the ability to communicate orally with students is essential. Clearly there is ample evidence of the value of online language teaching [16], [17] but the potential of technology to transform education in general is also well established [18], [19].

All of these findings suggest a critical need for planning and careful liaison between School technical support, ITS, University-level e-learning support, and instructional staff within the School. Most importantly, we believe there is a strong need for leadership.

\section{Discussion}

The findings from our School are not particularly positive as regards the state of e-learning and anecdotal evidence suggests that other Schools within the University face similar challenges. In spite of a general sense of staff good will towards e-learning and evidence of considerable effort to implement technology, we found the School's e-learning results to be disappointing. There were only a few instances of e-learning leading to pedagogical change, but frequent examples of technology being viewed merely as an 'add-on'. Online instructional practice has remained predominantly teacher-dominated, at least partly because the outstanding leadership and high-level teaching and technological skills that had previously existed on campus were channelled into commercial endeavours and then lost entirely to the University community. Basically, the promise of technology was not being fulfilled.

Further, since the conclusion of this study, support for e-learning initiatives at the University level has been eroded even further with the disestablishment of the central E-Education committee and the reassignment of the e-learning advisory functions to technical staff within ITS. We believe that such action illustrates a complete lack of understanding that e-learning is essentially pedagogical in nature and that a focus on technical issues is unlikely to lead to teaching and learning improvements.

Our findings are not revolutionary, nor are they unique. The promise of technology to transform learning (techno-utopianism) and its limitations in so doing have been thoroughly discussed in academic literature [2]. Problems identified elsewhere were reflected in our study's findings, for example, lack of teachers' technical skills and an administrative assumption that the personal transformation required for successful online teaching and learning is straightforward and easy. From our perspective though the most problematic issues were the failure to clearly define what was intended by the term 'e-learning' (to set knowable, achievable goals) and to systematically plan how those goals could be achieved. Not only are abstract or general statements about the need for computers to support teaching and learning processes not helpful, they can lead to confusion about expectations and anxiety, resistance, or frustration when goals are not achieved [5].

Given that there is an expectation within the University's strategic vision for the development of elearning expertise, that many staff acknowledge the potential of technology to support teaching and learning, and that most students anticipate easy access to online resources and tools within the tertiary environment, we considered all available options when making recommendations to our Dean and senior management at the university. Further, we understood that substantial financial input into e-learning was unlikely to occur.

We developed five major recommendations, all of which were designed to maximize the organization of staff expertise, provide a clear and visible sense of leadership and direction, increase dialogue about elearning possibilities and processes within our School and across Schools and generally address the types of issues described in our findings. A planning team has been established with its first task being to develop a clear description of e-learning as a construct, starting from the most basic types of goals, processes and skills required leading to more complex types of instructional approaches. The construct is being described by skill level, so that staff can identify where their expertise fits, in which areas personal development could be undertaken, and approximately how much time it might take to master new types of skills. Technical and teaching staff now meet online and face-to-face so that new computing developments can be explained and pedagogical approaches can be shared, debated, and trialled.

Finally, the Dean has become an enthusiastic supporter of our work and publicly acknowledges its importance within communications to the School and to senior university management, thus reinforcing the general perception that e-learning is not only worthwhile but is supported 'from the top'.

\section{Conclusion}

We believe that the situation as regards e-learning has changed from being excellent (perhaps five years ago) to being uneven across the university and, within our own School, to being mediocre. At the University level valuable technical and pedagogical expertise was commercialized, allowed to leave the university, and then 
was not adequately replaced. Further, within a small country like New Zealand, re-assembling a highly skilled e-learning team is not a simple task.

However, within our School staff good will and a desire to participate in building effective e-learning communities has persisted. Through increased dialogue, the development of clear organizational structures, and a shift toward well-defined goals and means of achieving them, we hope that substantial improvements will be made over the upcoming year as we switch to the Moodle environment. As Kopyc (2006) states "while we as computing staff, faculty, and administrators may not be there yet, the net generation students have arrived, and their increasing expectations for e-learning cannot be easily dismissed" [1].

\section{References}

[1] S. Kopyc, "Enhancing teaching with technology: are we there yet?" Innovate: Journal of Online Education, vol. 3, no. 2, December 2006. [Online]. Available: $\mathrm{http}: / / \mathrm{www}$.innovateonline.info/index.php?view=article\&id=74. [Accessed Dec. 5, 2006].

[2] A. K. Goldberg and F. J. Riemer, "All aboard - destination unknown: A sociological discussion of online learning" Educational Technology \& Society, vol. 9, no. 4, pp. 166-172, October 2006.

[3] A. Bonamici and D. Smith, "Initial results from ed tech survey: instructors," 8 May 2006, [Online]. Available: https://scholarsbank.uoregon.edu/dspace/handle/1794/3285. [Accessed Jan. 17, 2007].

[4] R. B. Kvavik and J. B. Caruso. "Convenience, communications, and control: how students use technology," 2005. [Online]. Available: http://www.educause.edu/LibraryDetailPage/666?ID=ERS0506. [Accessed Jan. 17, 2007].

[5] P. Butler, "Managing organisational change," Presented at the VLE: pedagogy and implementation online conference. 2006. [Online]. Available: http://www.onlineconference.net/vle2006/introduction.htm. [Accessed Nov. 22, 2006].

[6] University of Waikato, "The University of Waikato strategic plan, 2006-2009," 14 June 2006. [Online]. Available: http://www.waikato.ac.nz/vision/stratplan/. [Accessed June 14, 2006].

[7] M. Dobson, D. LeBlanc, and D. Burgoyne, "Transforming tensions in learning technology design: operationalising activity theory," Canadian Journal of Learning and Technology, vol. 30, no. 1, pp. 21-45, 2004.

[8] E. M.Johnson, A. Bishop, A. Holt, J. Stirling, and J. Zane, "Reflections in cyberspace: web-conferencing for language teacher education," Australian Journal of Educational Technology, vol. 17, no. 2, pp. 169-186, 2001.

[9] D. M. A. Sluijsman, F. J. Prins, and R. L. Martens, "The design of competency-based performance assessment in elearning," Learning Environments Research, vol. 9, no. 1, pp. 45-66, 2006.

[10] J. Brine and M. Franken, "Students' perceptions of a selected aspect of a computer mediated academic writing program: an activity theory analysis," Australasian Journal of Educational Technology, vol. 22, no. 1, pp. 21-38, 2006.

[11] D. R. Garrison, M. Cleveland-Innes, and T. Fung, "Student role adjustment in communities of inquiry: model and instrument validation," Journal of Asynchronous Learning Networks, vol. 8, no. 2, pp. 61-74, 2004.

[12] P. Hernández-Ramos, "How does educational technology benefit humanity? Five years of evidence," Educational Technology \& Society, vol. 9, no. 4, pp. 205-214, October 2006.

[13] K. Wijekumar, "Creating effective web-based learning environments: relevant research and practice," Innovate: Journal of Online Education, vol. 1, no. 5, June/July 2005. [Online]. $\quad$ Available: http://www.innovateonline.info/index.php?view=article\&id=26. [Accessed Dec. 5, 2006].

[14] C. Lomas and D. G. Oblinger, "Student practices and their impact on learning spaces," in Learning Spaces, D. G. Oblinger, Ed. Educause. 2006. [E-book] Available: http://www.educause.edu/learningspaces/.

[15] T. Anderson, "Distance learning - social software's killer ap?" 2005, [Online]. Available: https://eduforge.org/wiki/wiki/nzvle/wiki?pagename=ElggBased PortfolioPlan. [Accessed Oct. 13, 2006].

[16] U. Felix, "Teaching languages online: deconstructing the myths," Australian Journal of Educational Technology, vol. 19, no. 1, pp. 118-138, 2003.

[17] R. Chylinski, "Creating organizational environments supporting CALL teachers: a one-point perspective," PacCALL Journal, vol. 1, no. 1, pp. 9-28, 2005.

[18] A. Langlotz and G. Schiltz, "Ehistling - approaching English historical linguistics through concepts of blended learning," in International Conference on New Educational Environments (ICNEE), Neuchâtel, Switzerland, 2004, CDROM.

[19] M. Warschauer, D. Grant, G. Del Real, and M. Rousseau, "Promoting academic literacy with technology: successful laptop programs in K-12 schools," System, vol. 32, no. 4, pp. 525-537, 2004. 